\title{
Seasonal and spatial variations analysis of pollution status of Ondo coastal environment Nigeria using principal component analysis
}

\author{
Foluso O. Agunbiade, ${ }^{1 *}$ Bamidele I. Olu-Owolabi ${ }^{2}$ and Kayode O. Adebowale ${ }^{2}$ \\ ${ }^{1}$ Department of Chemical Sciences, College of Natural and Applied Sciences, Bell University of Technology, Ota, Nigeria \\ ${ }^{2}$ Department of Chemistry, Faculty of Science, University of Ibadan, Ibadan, Nigeria
}

(Received March 10, 2009; Accepted June 16, 2009)

\begin{abstract}
The variation in environmental quality of Ondo coast between seasons and sites were evaluated using principal component analysis (PCA). Seventeen metals were analysed in water and sediments with five anionic components further evaluated in water samples. The dry season concentrations of parameter and their degree of variation are higher than that of wet season. PCA of sediments revealed four parameter clusters and five clusters for water based on related sources of input, biogeochemical reactions or effects of physical conditions which are useful means of managing pollution when understood. The concentrations of sediment parameters were higher while their variations are narrower than for water parameters making sediment a veritable tool in coastal pollution monitoring. $\mathrm{Mg}$ is the most abundant metal in the sediment while $\mathrm{Na}$ and chloride are the most prominent in water. The incursion of saline water therefore plays a major role in the dispersion of pollutants and the water-sediment chemistry of the coast. The spatial variation based on the sediment parameters are much conservative than the water-based. Overall, site 9 and 10 were distinct from the others while sites 1 , 2, 3 related perfectly playing important roles in the sourcing and chemistry of pollutants in the coast.
\end{abstract}

Keywords: PCA, sediments, seasonal and spatial variation, metals, coastal area

\section{INTRODUCTION}

The coastal areas and estuaries are importantly transition zones between the wide wetlands and the coastal ocean. They are therefore valued nurseries and feeding regions for a large number of marine lives (Bilgili et al., 2005). Thus, conditions that impact negatively on the zones will have remarkable impacts on these vast coastal resources and on man. But, the perceived ability of the ocean to assimilate pollutants has informed the increasing practise of anthropogenic wastes disposal into the ocean leading to exposure risk of associated pollutants to lives. The estuarine and coastal sediments usually act as sinks receiving such wastes disposed and the riverderived trace metals from the weathering rock sources throughout the watershed (Martin and Windom, 1991; Zwolsman et al., 1996). To study such environment and the effects of discharge waste cluster analysis, an important tool that has been used in objects classifications, change detection, and pattern recognition (Bezdek, 1981; Bezdek and Pal, 1992; Abuelgasim et al., 1999; Liang et $a l ., 2005)$ will be appropriate. It has been used in real-

\footnotetext{
*Corresponding author (e-mail: foagunbiade@gmail.com)

*Present address: Department of Chemical Sciences, College of Natural Sciences, Redeemer's University, Km 46/48 Lagos-Ibadan Expressway, Redemption City, Mowe, Ogun State, Nigeria.

Copyright (C) 2010 by The Geochemical Society of Japan.
}

world analysis of market segmentation, business system planning, educational researches, agricultural planning, engineering studies, remote sensing and image processing (Punj and David, 1983; Abuelgasim et al., 1999; Wang and McCauley, 1996). Principal component analysis (PCA), a cluster analysis tool is a multivariate statistical technique that had been extensively used in studying patterns of environmental contaminants (Vogt, 1990; Szefer and Kaliszan, 1993; Shin and Lam, 2001; Hyun et al., 2006). Its potential in assessing metal behaviours in aquatic system had been reported in literature (Shine et al., 1995; Liu et al., 2003; Ip et al., 2006). This involves the ability to cluster together metals, with anions or organic matter to indicate complexation potential or related sources.

Further, the justifications for the use of statistical or empirical tools for environmental studies of dispersion, fates, and loadings of pollutants in the complex coastal environments are the limitations of less understanding and the dynamic nature of the physical factors like light penetration, temperature, waves, turbulence, current, tides among others on the environment (James, 2002). These put some measures of doubt to the effectiveness of purely mechanistic models' application in this type of environment. The biogeochemical reactions in these coastal zones are governed by these factors also which change seasonally. The frequency of rainfall affects the pollutants' contributions from urban, roof and road runoffs, pollutants' 


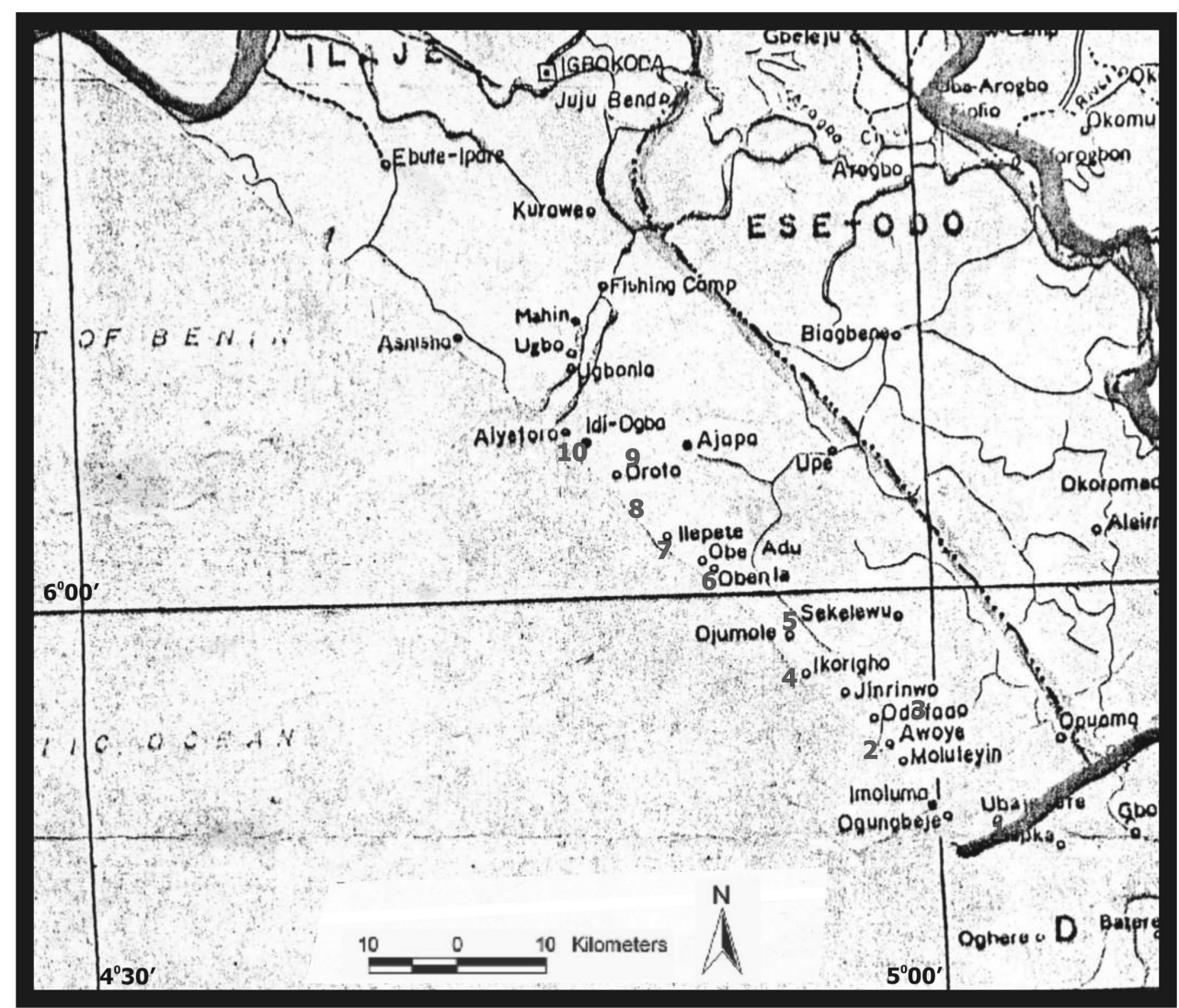

Fig. 1. Map of the Coastal Area of Ondo State and the sampling point.

atmospheric precipitation and their washing from the geological structural framework or soils from the watershed through erosion. Thus, these variables remarkably affect the dispersion of pollutants in the coastal zones and need to be fully known and carefully considered to effectively model and understand the state of this compartment of the environment. Moreover, important factors considered in evaluating pollution and toxicity of pollutants to man, other lives and the ecosystem are the measures of their bioavailability, biological effects (bioactivity), the accumulative tendencies (biomagnification) of such pollutants. These factors are equally affected by seasonal changes in climatic and physical conditions witnessed in costal environment (James, 2002). The limitation in understanding this medium of the environment, the coast, further favours the use of empirical knowledge over causal-based models.

Hence, evaluation of pollutants in sediments and water of this zone, its clustering pattern and variation with seasons could effectively model the pollutants impact on the zone. This will reveal the needs to place more focus on investigation of pollutants and serious regulation of the coastal areas especially in third world countries and developing economies which thus far had less efforts in this direction.

The coastal area of Ondo State, Nigeria, is used as an example. The determination of cluster patterns of pollutants and their dispersion in the environment due to seasonal changes of climatic and physical conditions are undertaken as it is imperative to the understanding of how these factors affect the pollutants fate and pollution status of coastal area. There is recently increasing focus in literature on investigations of environmental cluster pattern of pollutants and seasonal variation in quality of the environment especially in developing countries. Therefore the objective of the study is to present a methodology of empirically evaluating changes in pollutant dispersion in coastal area due to variation in climatic or physical conditions using PCA.

\section{Materials AND Methods}

\section{Study area}

The coastal region of Ondo State (Lat. $5^{\circ} 50^{\prime} \mathrm{N}-6^{\circ} 09^{\prime}$ $\mathrm{N}$ and Long. $4^{\circ} 45^{\prime} \mathrm{E}-5^{\circ} 05^{\prime} \mathrm{E}$ ) is an estuarine coastal zone with an entry point at Awoye (Site 2 - Lat. $5^{\circ} 54^{\prime} \mathrm{N}$ Long. $4^{\circ} 59^{\prime} \mathrm{E}$ ) where there is exchange of water between the upland wetlands and the Atlantic Ocean (Bright of Benin). 
The details of the coordinates of the sampling sites were presented in our earlier study (Adebowale et al., 2008a). The water close to this estuarine point is brackish indicating continuous sea water intrusion. The total area covered by the watershed is over $2000 \mathrm{~km}^{2}$ while this study was conducted in an area of about $500 \mathrm{~km}^{2}$ close to the coastal ocean (the estuarine point). The climatic condition of the area involves the wet season (April-October) and dry season (November-March). During the wet season, the average rainfall index is about $3000 \mathrm{~mm}$ while the mean temperature is $28^{\circ} \mathrm{C}$. The average rainfall index for the dry season is $800 \mathrm{~mm}$ and the mean temperature is $32^{\circ} \mathrm{C}$.

There are dispersed communities within the coast and a fast growing population size of less than a million people. The vast majority of the settlements scattered around the coast dispose their waste generated by domestic activities directly into the water while there is crude oil exploration at Ukua (Site 1 - Lat. $5^{\circ} 50^{\prime} \mathrm{N}$ Long. $5^{\circ} 04^{\prime} \mathrm{E}$ ). This classified the area as one of the region called Niger Delta zone in Nigeria. The rivers and streams that traverse several settlements of the coast discharge into the open ocean through this estuary and there are exchanges of water between the ocean and the coastline. Commercial activities in the area are carried out in speedboats used for transportation of goods and people in the area while heavy fishing activities are also involved in the area. This study selected ten sampling points (Fig. 1) for the evaluation within the wet season (April 2006) and dry seasons of (January 2007). Sampling points' choices were based on observed economic activities, nearness to settlements; the oil exploration point and distance to the discharge point into the ocean. The crude oil exploration, the domestic activities and none existence of any waste treatment plant in the area gives strong indications of pollution in the area. The total numbers of sites selected are representative of the coastal environment. There is however a need to understand its seasonal changes.

\section{Sampling and preservation of samples}

Thirty different samples of water and twenty samples of sediments were collected from different locations along the coast. The sampling points were stratified based on closeness to settlements, the inlet/outlet to the ocean and other observed activities that can cause pollution. Sampling was done by switching off the engine of the commercial speedboat and lowering the sample containers to fill over a distance and a period of time. Prior to sampling, all sampling equipments were pre-treated as specified by APHA (1995). High density polyethylene (HDPE) bottles were used to collect samples for the determination of parameters like chloride, sulphate, nitrate-nitrogen, and phosphate. These samples were all preserved at $4^{\circ} \mathrm{C}$ in an ice chest for transportation to the laboratory and were refrigerated at $4^{\circ} \mathrm{C}$ in the laboratory till analysed. Also, samples of a litre each per sampling point were collected for determination of 17 metals using HDPE bottles. Samples for metal determination were preserved with $2 \mathrm{ml}$ of conc. $\mathrm{HNO}_{3}$ (Ultrex) per litre and keep at $4^{\circ} \mathrm{C}$ till analysed. The sampling quality control was ensured by introducing bottle blanks and field replicate samples which were analysed to measure integrity of samples and reproducibility respectively. The blanks were less than $5 \%$ of the parameters determined in samples while the replicate samples concentrations have relative standard deviation (RSD) between $8-16 \%$. Bottom sediment samples were collected after sampling for water analysis to avoid introduction of interference by the resuspension of settled sediment particles. The sampling of sediments were done with Van veen grab sampler while samples were kept in aluminium foil and air-dried before analysis. The periods between sampling and analysis were however kept between the recommended times by Standard Methods (APHA, 1995).

\section{Chemical analysis}

Water samples collected were analysed for some inorganic non-metallic constituents (chloride, sulphate, phosphate and nitrate) and 17 metallic constituents. The methods adopted for the analysis are as specified by Standard Methods for Examination of Water and Wastewater (APHA, 1995). Sulphate, nitrate and phosphate were determined by spectrophotometric method of analysis and chloride was determined with Argentometry titration. The metal analyses were done by the digestion of the water samples with concentrated nitric acid (Ultrex) to release the organic bound metals and those in particulate or adsorbed on particulates. The digestion was done in glassware previously soaked in nitric acid and washed with demineralised water. The digested samples were analysed for metals in duplicate using a Buck Scientific Flame Atomic Absorption Spectrophotometer Model 205. All other analyses in the water samples were done in triplicate and the mean value presented. Sample blanks were also analysed and results which were between $1-6 \%$ of each metal determined in samples were used to correct for any contamination in the course of analysis.

The sediment samples were analysed for 17 metals and total organic carbon (TOC). The sediment samples were grinded lightly in mortals thoroughly mixed and sieved in standard sieves of graduated sizes. Less than $200 \mu \mathrm{g}$ grain size fractions of each sieved sediment samples were used for the analysis. $500 \mathrm{mg}$ of the sediment were accurately weighed and digested with concentrated nitric acid (Ultrex). The digested samples were made up to $100 \mathrm{ml}$ in volumetric flask and analysed for the metals. The quality control of the method was determined by the analysis of a known standard sample obtained from 

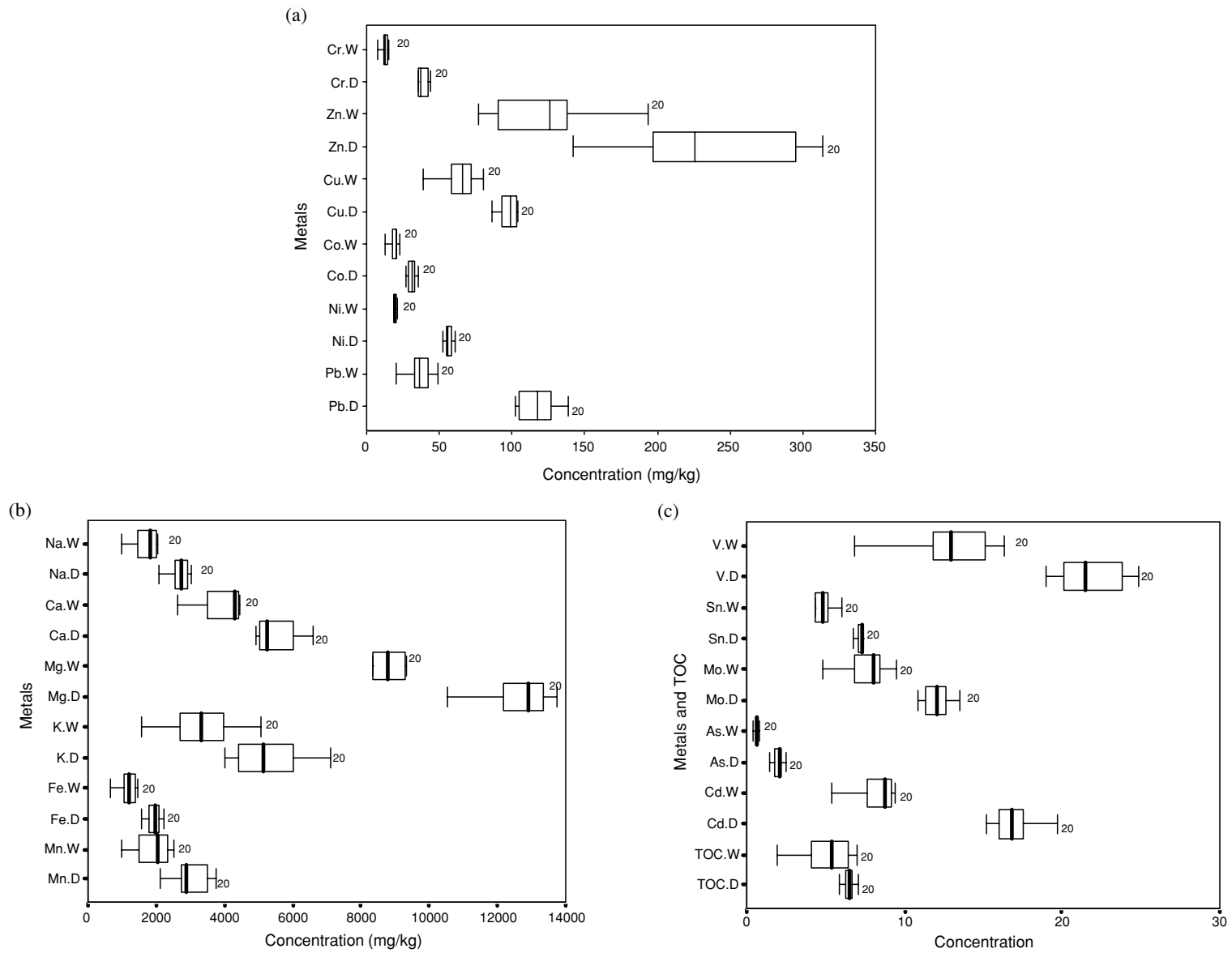

Fig. 2. Box and whisker presentation of 17 metals and total organic contents in sediment samples from all sites between the two seasons (W represent wet season and D represent dry season). The units of the metals are in $\mathrm{mg} / \mathrm{kg}$ while that of TOC is percentage (\%). The vertical bars in the box are the median values; the ends of the whiskers are the extreme data while the edges of the boxes present half that data point between the medians and extremes. The number of data points in each parameter is given on each box and whisker plot.

USA National Institute of Standards and Technology (NIST) Standard Reference Material and subjected to same process as the sample so as to determine accuracy and precision of the method used. The standard sample analysed show recovery values ranging from $91-103 \%$ of the prepared standard. TOC determination was determined using Walkey-Black Method.

\section{Data analysis}

The outcome of chemical analysis of the pollution parameters were taken through a chemometric data mining process which includes both univariate and multivariate methods using the complete dataset. Thus, they are presented in box and whiskers format. The variations between seasons were further evaluated by the comparison of means in each parameter between seasons using student $t$-test. Principal Component analysis (PCA) a multivariate tool for establishing cluster of data was fi- nally used to measure and compare differences in sites and parameters among seasons. All data analysis was done with SPSS 11.

\section{RESULTS}

\section{Sediment quality parameters}

The box and whisker presentations of metals and organic carbon content in sediments between the two seasons are presented in Figs. 2(a)-(c). This presentation provides a good overall impression of the differences between seasons. A common trend observed in the results is that the concentrations of the metals in the sediments at the dry season (represented by .D) are higher than the wet season (represented with .W). Also, the ranges of the metals concentrations, measured by the ends of the whiskers, show wider variations during the dry season than the wet season for most metals. These ranges of metals for 
(a)

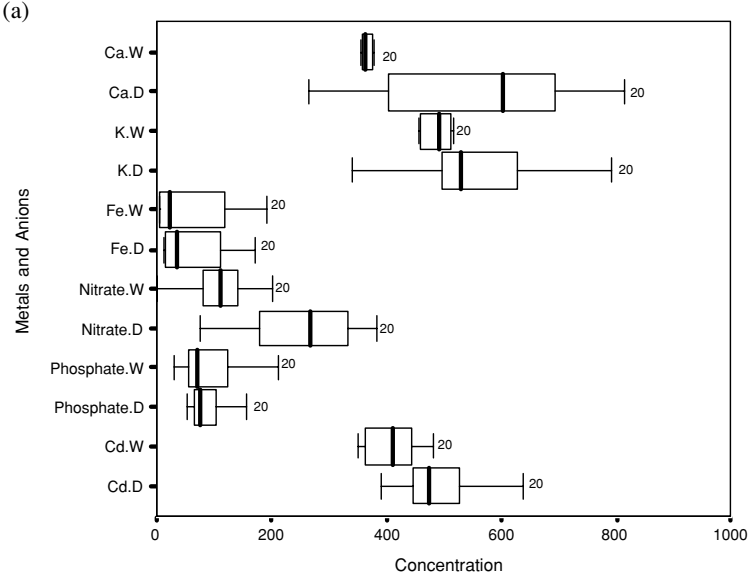

(b)

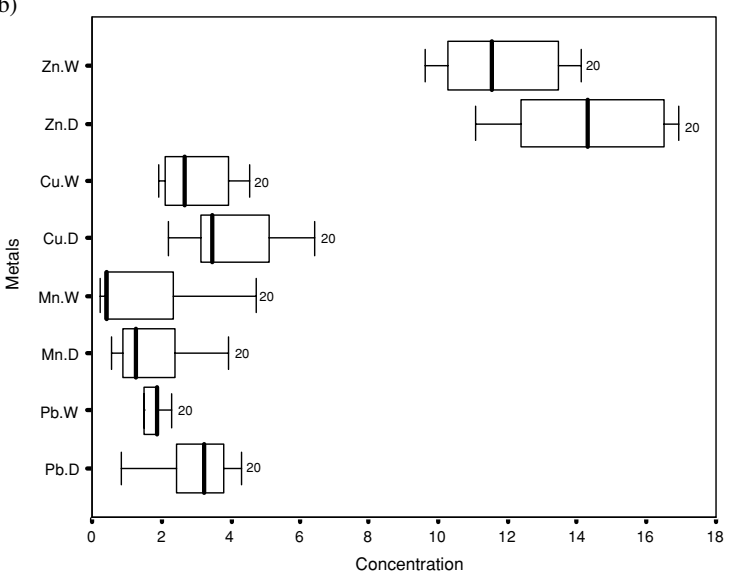

(c)

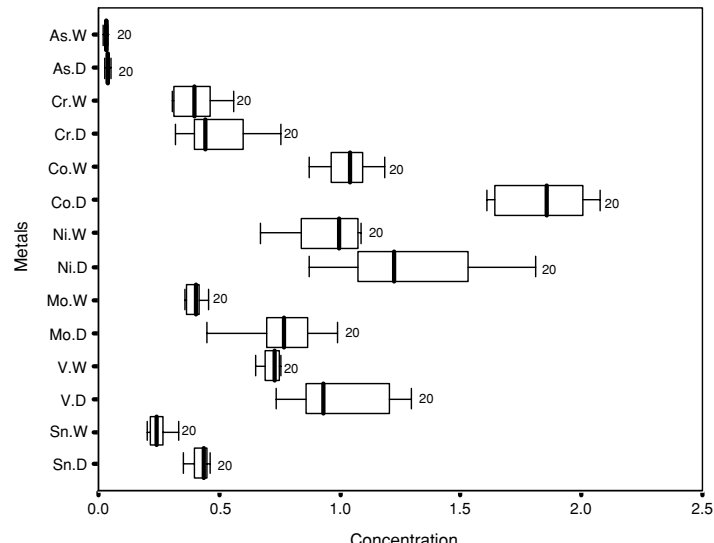

(d)

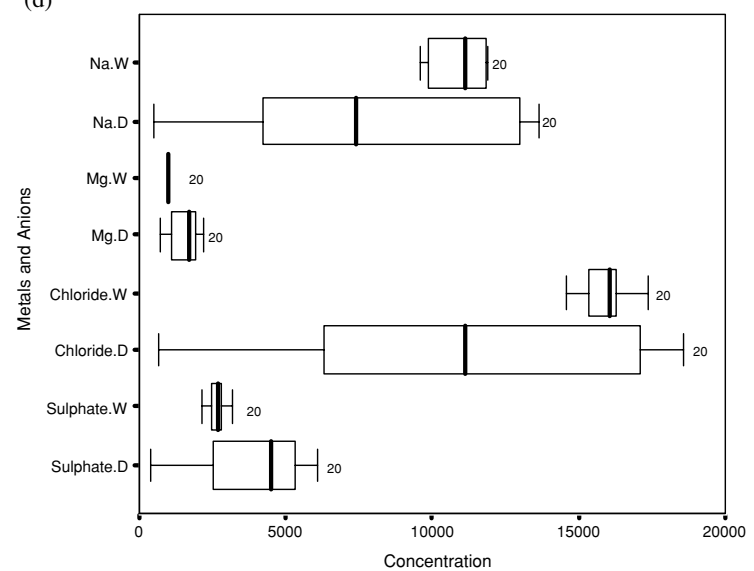

Fig. 3. Box and whisker presentation of 17 metals and anionic components in water samples from all sites between the two seasons (W represent wet season and D represent dry season). The units of the parameters are in $m g / L$ except Cd, phosphate and nitrate which are in $\mu \mathrm{g} / L$. The vertical bars in the box are the median values; the ends of the whiskers are the extreme data while the edges of the boxes present half that data point between the medians and extremes. The number of data points in each parameter is given on each box and whisker plot.

the seasons revealed that $\mathrm{Cr}, \mathrm{Co}, \mathrm{Ni}, \mathrm{Fe}, \mathrm{Sn}$, As are conservative for both seasons and TOC in the dry season being that they varied less widely than the other parameters. The concentrations of Mg during the two seasons are the largest observed in the estuary. This is because soilrelated elements like $\mathrm{Al}$ and $\mathrm{Mg}$ have been reported widely to exist in aluminosilicate matrix of sediments (Huang et al., 1994; Zelenka et al., 1994; Atgin et al., 2000; Kumar et al., 2001; Pekey, 2006). Na, Ca, Mg, K, Fe and Mn (Fig. 2(b)) were the major metal contents observed in the sediments for both seasons (above $1000 \mathrm{mg} / \mathrm{kg}$ ). The concentration of arsenic is the least in all the sites. The skew pattern of the data did not show any notable pattern. The statistical treatment done to compare means of each parameter in the sediments between the two seasons was done by the student $t$-test at $95 \%$ confidence limit. It shows a significant difference between the seasons for all parameter investigated in the study which indicates that the quality status of the environment, the physical factors and the biogeochemical reactions governing the fate of the contaminants are different between the two seasons. Finally, the concentrations of the parameters investigated in the sediments were many magnitudes higher than the water samples and with relatively less variation. This is because sediment has been reported as sinks (Adams et al., 1992; Rowlatt and Lovell, 1994; Mucha et $a l ., 2003)$. Thus, it is preferred for monitoring environment pollution of aquatic systems because it exhibit reduced variation spatially and temporally (Beiras et al., 2003; Caccia et al., 2003; Pekey, 2006).

\section{Water quality parameters}

Metals and anionic components that were evaluated in water sample are presented in box and whisker format in Figs. 3(a)-(d). The ranges of most of the parameters as well as their concentrations during the dry season are 
wider and higher than at the wet season similar to sediment results. Nitrate was not detected in one of the sites during the wet season. The concentration of $\mathrm{Na}$ and chloride was the highest in the water sample as against $\mathrm{Mg}$ in sediments which is due to seawater incursion into the estuary. The high variation, reflected by the wider range, noticed in the parameters like $\mathrm{Ca}, \mathrm{K}$, chloride, sulphate, $\mathrm{Mg}, \mathrm{Na}, \mathrm{Co}, \mathrm{Ni}, \mathrm{Mo}, \mathrm{V}, \mathrm{Cd}, \mathrm{Pb}$ especially during the dry season are indication of changes in parameters' concentrations as distance increases from the estuary discharge point and the crude oil exploration platform which are sources of pollutants' input and means of their transport or dispersion into the coastline. This implies that the reduced physical mix during the dry season create an opportunity for the appreciation of the trend of pollutant dispersion in the coast being that a near steady state is probable. $\mathrm{Mg}, \mathrm{Sn}$ and As are conservative parameters in both season while $\mathrm{Ca}, \mathrm{Pb}, \mathrm{Mo}, \mathrm{V}$, chloride and sulphate were observed to be conservative during the wet season. The test of significance differences between the parameters' mean ( $t$-test) indicate that there are significant differences for all parameters between the two seasons except for arsenic. The wider parameters' ranges observed for both water and sediment samples in the dry season strongly indicate that the chemical composition of the two environmental media is significantly influenced by the physical mix which is witnessed in the wet season. Likewise, the higher concentrations of most water quality parameters during the dry season suggest further that increased atmospheric precipitation during the wet season dilute the parameters' concentrations during the wet season.

\section{Discussion}

\section{Principal component analysis of sediment samples}

The understanding of the cluster pattern of quality parameters' data used in this study will help gain further insight into the chemistry of the pollutants so as to measure the quality of the environment and to plan a clean up process for the pollutant were applicable. This requires the use of statistical models. PCA has been reported useful in this regard (Liu et al., 2003, Ip et al., 2006). Thus, PCA loading plot of the metals and organic matter (TOC) in sediment samples within the two seasons is presented in Fig. 4. The sampling sites were the objects while the investigated parameters were the variables. The result of the PCA classified the quality parameters in the sediment into five distinct clusters with some other dispersed parameters (Fig. 4). The first group (G1) are metals natural to the environment and are introduced by natural events like erosion of the soil, seawater incursion among others which are prominent during the wet season compared to the other season. This is reflected by the association of

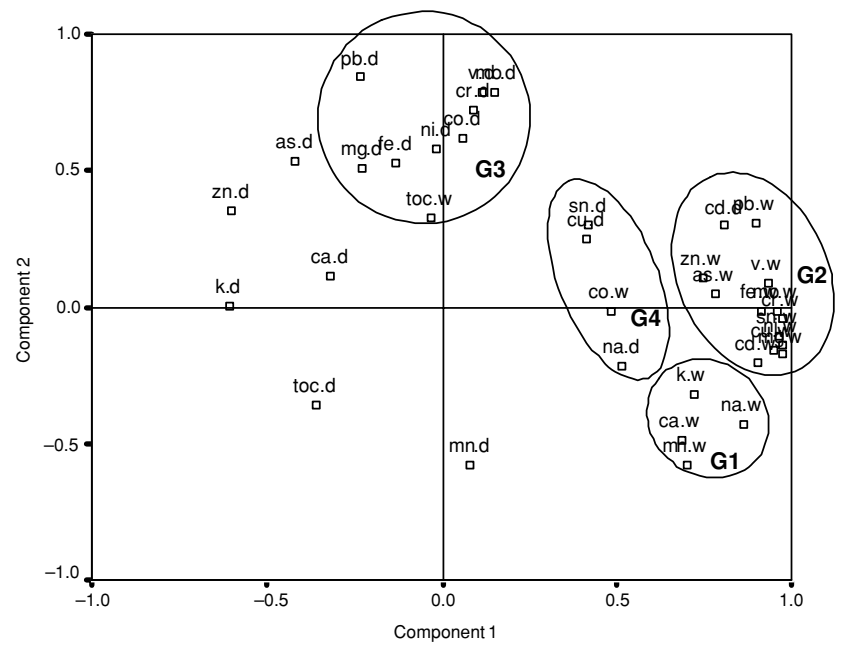

Fig. 4. Principal Component Analysis of 17 metals and TOC in sediment samples during the both seasons ( $W$ - represent wet season data while $D$ - represent dry season data).

the metals with wet season measurements. The metals are most probably affected by similar physicochemical factors but their presence is of less negative effects on lives in the aquatic habitat. The second group of metals in sediments (G2) are those contributed by adverse anthropogenic activities. The metals in this group are toxic to human life and the ecosystem. They have been used as marker or tracers of industries impacts on the environment (Jervis et al., 1993; Nkono et al., 1999; Kumar et al., 2001; Lin et al., 2002; Gallego et al., 2002; Loska et al., 2004). Their cluster pattern shows that they are strongly associated and are parameters measured in wet season but different from the other season and cluster of other metals. The influence of physical conditions and source of inputs on the fate, loading and dispersion of these metals during the wet are strongly related and distinctly different from the dry season. These and their detail knowledge will be very useful in ensuring the clean up of these metals from the environment. Only $\mathrm{Cd}$ in the dry season clustered with this group which indicates that there is significant change in the status and the chemistry of $\mathrm{Cd}$ between the seasons investigated. Overall, an insight into the factors influencing the metals and their biogeochemistry will be important to the control of their toxicity. Furthermore, group three (G3) parameters are also associated parameters which are contributed by uncontrolled anthropogenic activities adversely affecting the environment. The metals in this group are dry season measures of G2 metals. This third cluster pattern depicts that different sets of factors affect concentration, fate and dispersion of these metals in the dry season relative to the wet season except for organic matter that related with 
the group. Likewise, an understanding of the geochemical reactions and physical conditions in dry season affecting these parameters will help in effectively managing their contributions and adverse effects on lives and the environment. The most probable sources of parameters in G2 and G3 are crude oil exploration activities and uncontrolled domestic waste discharge as reported in our previous study (Adebowale et al., 2008b). Ultimately, the group four (G4) metals in sediments are $\mathrm{Cu}, \mathrm{Sn}$ and $\mathrm{Na}$ in dry season and wet season Co. These metals are of less risk to live except $\mathrm{Sn}$. They are governed by related factors. It is difficult to place what class $\mathrm{Mn}, \mathrm{As}, \mathrm{Zn}, \mathrm{Ca}, \mathrm{K}$ and TOC measured in the dry season sediments because they are completely different from others groups and are not govern by any similar reactions with the others reported. The effect of organic carbon on the metal partitioning and distribution is not evident in this study as none of the TOC associated with their corresponding class of metals which implies that the formation of complexes with chloride, $\mathrm{OH}^{-}$and other inorganic ligands influence the chemistry of the environment than organometallic complexation.

\section{Principal component analysis of water samples}

The PCA and the seasonal variation of water quality parameters did not show as much distinct cluster pattern as seen in sediments. This is because of the dynamic nature of the water column, the high perturbation witnessed in tidal water of coastal region and the effects of increased atmospheric precipitation. These increase the degree of physical mixing of the water column with the pollutants and introduce seasonal wider differences in parameters' patterns. Despite this, five clusters of parameters can be identified from the analysis (Fig. 5). First cluster (W1) contains $\mathrm{Ca}, \mathrm{Mg}$, nitrate and sulphate all measured in the dry season samples. They are equal parameters with near perfect superimposition indicating that $\mathrm{Ca}$ and $\mathrm{Mg}$ exist as salts of the associated anions during the season. These two metals are likely partitioned from the sediment phase being that the sediment results showed enrichment of sediments with these metals. Due to the solubility of these metals' salts formed in water, they are partitioned into the water column.

Moreover, the second group (W2) are strongly related parameters with similar biogeochemical reactions governing their fate. Some of the metals within the group $(\mathrm{Cr}, \mathrm{Mn}$, and $\mathrm{Fe})$ are redox sensitive and are affected by changes in dissolved oxygen, chloride concentration, microbial activities among others. They are likely contributed into the environment by combined effects of natural events like erosion of the geological matrix in the zone contributing $\mathrm{Fe}$ and $\mathrm{Mn}$; seawater incursion which introduces $\mathrm{Na}$, chloride, sulphate and adverse human activities that introduce $\mathrm{Pb}, \mathrm{Cr}$, and $\mathrm{Co}$. Within the group, there

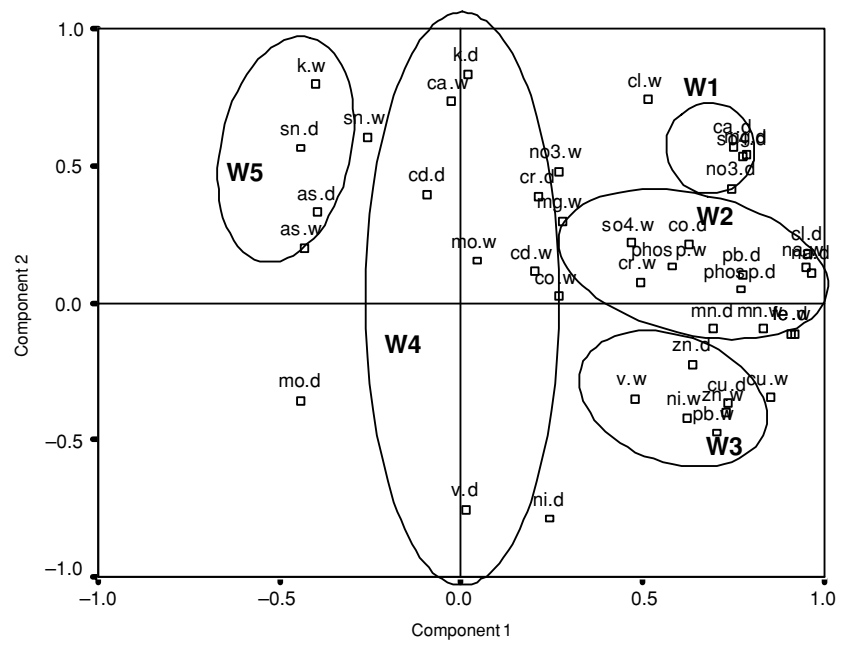

Fig. 5. Principal Component Analysis of 17 metals and 5 anionic components in water samples during the both seasons ( $W$ - represent wet season data while D - represent dry season data).

are some parameters with higher level of interaction than the others. Na during the dry season; chloride during the wet season are much related. This implies that there is no much variation in $\mathrm{Na}$ contribution between the seasons except for chloride that varies. The close association of $\mathrm{Na}$ and chloride in dry season measure established the view that the major means of pollutant transport into coastal zone and important factor affecting the partitioning of the metals is the incursion of the saline water from the coastal ocean. This plays a major role in the water chemistry of the area. The deviation of chloride cluster pattern during the wet season indicates that chloride has additional sources of contribution which is associated with atmospheric precipitation and other physical conditions peculiar to the wet season. Further within the group, Fe is equal for the two seasons thus it has a conservative source and biogeochemical reactions regardless of seasons. The closeness in the plot of Mn for the two seasons and with that of $\mathrm{Fe}$ is equally notable. The two metals are redox sensitive and will have very similar reactions. Fe has been reported to form complexes by binding more with hydroxyl ion $\left(\mathrm{OH}^{-}\right)$because of the low polarisation of $\mathrm{Fe}^{3+}$ (Stumm and Morgan, 1996; Korfali and Davies, 2004). Mn being similar will follow the same pattern. Thus, the abundant presence of $\mathrm{OH}^{-}$in the aquatic environment in the two seasons account for the conservative trend of the two metals. $\mathrm{Pb}$ related perfectly with phosphate in dry season data. Thus, a possible combination of these two ions is vivid and a modification of its chemistry to favour precipitation of $\mathrm{Pb}$ from this combination in the water column will reduce its bioavailability. The last set of related parameters within the group is $\mathrm{Cr}$, phos- 


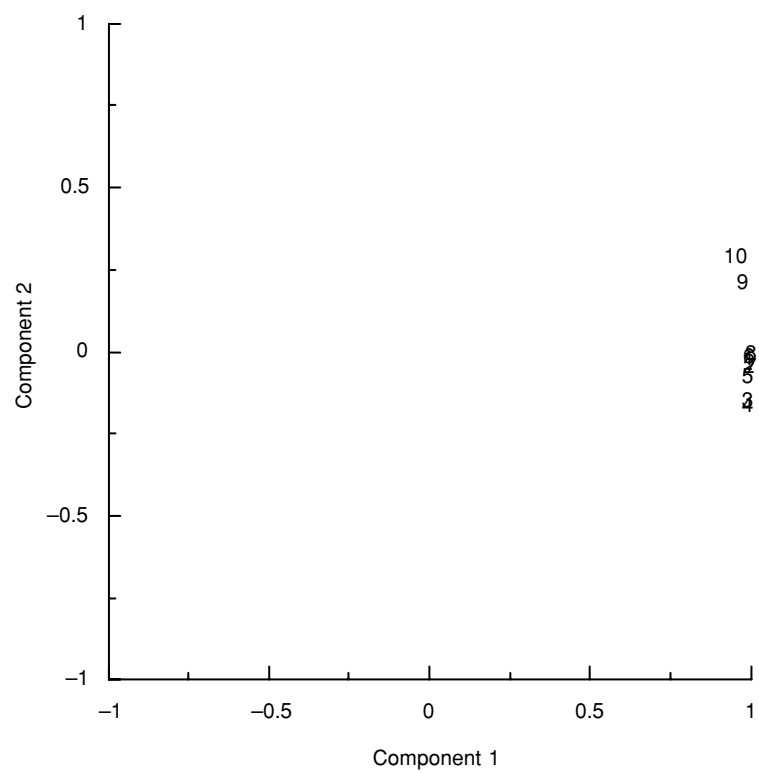

Fig. 6. Principal Component Analysis of site variation during both seasons using sediment quality parameter data.

phate and sulphate in the wet season values and Co in the dry season. Cr therefore exists as phosphate and sulphate within the water column and is governed by the same physicochemical factors with Co in the dry season. $\mathrm{Cr}$ could be removed from the water column by modification of the associated anion to form insoluble $\mathrm{Cr}$ salts or complexes.

The next group of parameters (W3) are strongly related cluster of transitional metals that have been reported present in crude oil. There is therefore a strong indication of crude oil exploration being the source of their input into this environment. The presence of $\mathrm{Zn}$ and $\mathrm{Cu}$, both evaluated in the two seasons, in this group is a reflection that their input sources are closely related; their reactions similar; the effects of physical conditions on them the same regardless of season. An effective management of the crude oil exploration platform will ensure the control of these metals in the coast particularly V, Ni and $\mathrm{Pb}$. The fourth cluster (W4) is identified based on their cluster pattern along the 0.0 -axis of the Component 1 other than the extent of their relationship with one another. These parameters are related to both domestic wastes and crude oil exploration discharge. There is no variation in $\mathrm{Cd}$ concentration between the two seasons which is similar to the result obtained from PCA of sediment samples. This suggests that the sources of $\mathrm{Cd}$ discharge and its reactions are seasonal independent. Other parameters within this group expressed seasonal changes. The moderate association of $\mathrm{Cd}$ and $\mathrm{Ca}$ in the group is largely due to the similar ionic radius of $\mathrm{Cd}$ and $\mathrm{Ca}$ which is $0.97 \AA$ and $0.99 \AA$ respectively which make them to

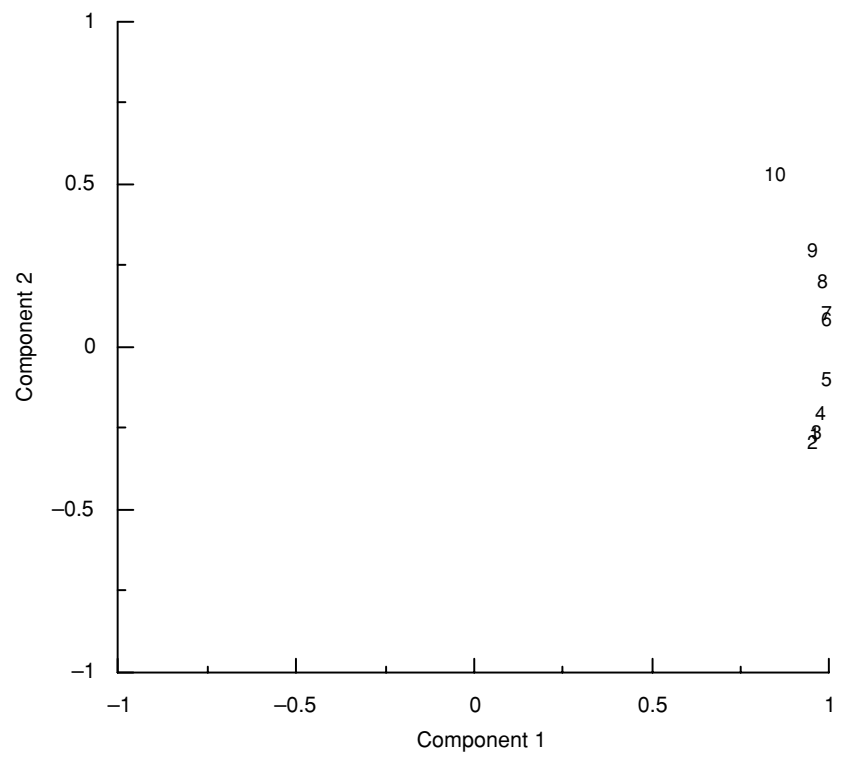

Fig. 7. Principal Component Analysis of site variation during both seasons using water quality parameter data.

have a tendency of acting as camouflaged element against each other in their salts or complexes (Reeder, 1996; Ianni et al., 2000; Korfali and Davies, 2004). Wet season measures of nitrate, $\mathrm{Mg}, \mathrm{Cd}, \mathrm{Co}$ and dry season evaluation of $\mathrm{Cr}$ within the group were more closely related than the others. Ni and V are dissimilar to the others as reflected by their position in Component 2. There is high tendency that they are only sourced from crude oil mining while others have other sources of input but are affected by similar factors. $\mathrm{Ca}$ in the dry season and $\mathrm{K}$ in wet also related closely from the PCA.

Finally, the fifth cluster of data indicates a nonvariation in Sn and As between the two seasons (W5). The conservation result observed for these two parameters is an indicator to the fact that they are resistant to changes in the environment which gives them higher tendency of bioaccumulation and increase toxicity have been toxic (Lau, 1991; Clark et al., 1988) to lives and the ecosystem.

\section{PCA of spatial variation}

The PCA plotting for site variation study using all sediment quality parameters investigated in this study for the two seasons is presented in Fig. 6 while that of the plotting on all water quality parameters is presented in Fig. 7. A comparison between the two figures revealed that the spatial variation based on water quality parameters varies more widely that that of the sediment parameters. This confirms that sediments are conservative and exhibit less spatial and temporal variability (Pekey, 2006) making them veritable tools for environmental pollution 
monitoring. The wider variation in the sites from water column is because of the changing turbulence of water column temporally or spatially and the various reactions influencing the partitioning and distributions of the parameters. This implies that the water chemistry of coastal water is more complex compared to the sediment.

Within the PCA sediment-based plot (Fig. 6), site 9 and 10 are closely distinct and vary from the other sites and from each other. The two sites are distant from the crude oil exploration site (site 1) and the estuary discharge point (site 2). The salinity values of these sites are much reduced especially during the dry season. Though, the sites are near to the settlements which are probable sources of domestic waste-based contaminants, they are less affected by pollution relative to other sites and reduced salinity implying a reduced tendency of metals partitioning into the sediment phase. Further, site 3, 4 overlap in the plot (Fig. 6) which shows that the pollution status, the prevalent biogeochemical reactions in the two sites are equal. The source inputs of pollutants into the two sites are also strongly related being neighbouring sites to each other which implies that the two sites could be managed together. Sites $1,2,6,7$, and 8 are equal on the PCA plot while site 5 stands in-between the two last clusters identified. The perfect cluster relationship of site 6,7 , and 8 indicates a downstream spread of pollutants from site 6 to 8 and means that reactions governing transport of these pollutants in the sites are the same even with that of site 1 and 2. Our earlier study have shown site 1 as a major source of metal input; site 2 as the source of salinity changes which plays a major role in metal partitioning and transport and that there were evidence of contributions from domestic wastes discharge (Adebowale et al., 2008b). Thus, the perfect relationship within these sites established this view which means that pollutants dispersion and partitioning favouring sediment phase are prevalent in the sites 1 and 2 based on crude oil exploration while pollutants dispersion and similar partitioning into the sediment based on domestic waster discharge are prevalent in sites 6,7 , and 8 . The water based PCA plot (Fig. 7) also distinguished sites 8, 9, ad 10 which is similar to the site 9 and 10 distinguished in sediment. Sites 5 and 4 are also distinct from each other and from other sites. Site 6 and 7 were equal in the plot while site 1, 2, and 3 are also superimposed in the plot. This confirms the earlier roles reported of activities in site 1,2 , and 3 on the water and sediment chemistry of the area and that of the domestic activities in the other sites.

\section{Conclusion}

This study has revealed that:

- Metals in sediment being introduced by anthropogenic activities are governed by similar factor in each season which is different for others season and the understanding of which will be useful in managing them.

- Dry season measures were higher and varies widely which indicate that pollutants' dispersion are best understood when forceful turbulence and physical mix is reduced and steady state condition prevalent.

- Sediments compositions are more stable and possess higher concentration being sinks and are reliable tools for measuring impacts.

- Spatial variation of sediment are more conservative than that of water while site 10 and 9 are distinct in both water and sediment while site 1, 2, and 3 are more related and plays important role in sourcing pollutants, dispersing them and influencing their chemistry.

\section{REFERENCES}

Abuelgasim, A. A., Ross, W. D., Gopal, S. and Woodcock, C. E. (1999) Change detection using adaptive fuzzy neural networks: Environmental damage assessment after the Gulf War. Rem. Sens. Environ. 70, 208-223.

Adams, W. J., Kimerle, R. R. and Barnett, J. W. (1992) Sediment quality and aquatic life assessment. Environ. Sci. Technol. 26(10), 1864-1875.

Adebowale, K. O., Agunbiade, F. O. and Olu-Owolabi, B. I. (2008a) Impacts of natural and anthropogenic multiple sources of pollution on the environmental conditions of Ondo State coastal water, Nigeria. Electronic Journal of Environmental, Agriculture and Food Chemistry 7(4), 27972881.

Adebowale, K. O., Agunbiade, F. O. and Olu-Owolabi, B. I. (2008b) Fuzzy comprehensive assessment of metal contamination of water and sediments in Ondo Estuary, Nigeria. Nigeria. Chemistry and Ecology 24(4), 269-283.

APHA (1995) Standard Method for Examination of Water and Wastewater. American Public Health Association.

Atgin, R. S., El-Agha, O., Zararsız, A., Kocatasş, A., Parlak, H. and Tuncel, G. (2000) Investigation of the sediment pollution in Izmir Bay: trace elements. Spectrochim. Acta Part B 55, 1151-1164.

Beiras, R., Bellas, J., Fernández, N., Lorenzo, J. I. and CobelaGarcía, A. (2003) Assessment of coastal marine pollution in Galicia (NW Iberian Peninsula); metal concentrations in seawater, sediments and mussels (Mytilus galloprovincialis) versus embryo-larval bioassays using Paracentrotus lividus and Ciona intestinalis. Mar. Environ. Res. 56, 531-553.

Bezdek, J. C. (1981) Pattern Recognition with Fuzzy Objective Function Algorithms. Plenum, New York.

Bezdek, J. C. and Pal, S. (1992) Fuzzy Models for Pattern Recognition: Methods that Search for Structures in Data. IEEE Press, Piscataway, N.J.

Bilgili, A., Proehl, J. A., Lynch, D. R., Smith, K. W. and Swift, M. R. (2005) Estuary/ocean exchange and tidal mixing in a Gulf of Maine Estuary: A Lagrangian modeling study. Estuar., Coastal Shelf Sci. 65, 607-624.

Caccia, V. G., Millero, F. J. and Palanques, A. (2003) The distribution of trace metals in Florida Bay sediments. Mar. Pollut. Bull. 46, 1420-1433. 
Clark, E. M., Robert, M. S. and John, N. L. (1988) The fate of tributyltin in the aquatic environment. Environ. Sci. Technol. 22, 600-604.

Gallego, J. L. R., Ordónez, A. and Loredo, J. (2002) Investigation of trace element sources from an industrialized area (Avilés, northern Spain) using multivariate statistical methods. Environ. Int. 27, 589-596.

Huang, X., Olmez, I. and Aras, N. K. (1994) Emissions of trace elements from motor vehicles: potential marker elements and source composition profile. Atmos. Environ. 28(8), 1385-1391.

Hyun, S., Lee, T., Lee, C. H. and Park, Y. H. (2006) The effects of metal distribution and anthropogenic effluents on the benthic environment of Gwangyang Bay, Korea. Baseline/ Mar. Pollut. Bull. 52, 104-120.

Ianni, C., Magi, E., Rivaro, P. and Ruggieri, N. (2000) Trace metals in Adriatic coastal sediments: distribution and speciation pattern. Toxicol. Environ. Chem. 78, 73-92.

Ip, C. C. M., Li, X. D., Zhang, G., Wai, O. W. H. and Li, Y. S. (2006) Trace metal distribution in sediments of the Pearl River Estuary and the surrounding coastal area, South China. Environ. Pollut., doi:10.1016/j.envpol.2006.06.028.

James, I. D. (2002) Modelling pollution dispersion, the ecosystem and water quality in the coastal waters: a review. Environmental Modelling Software 17, 363-385.

Jervis, R. E., Ko, M. M. C., Junliang, T. and Puling, L. (1993) Multivariant analyses of trace element patterns for environmental tracking. Journal of Radioanalytical and Nuclear Chemistry 169(2), 363-379.

Korfali, S. I. and Davies, B. E. (2004) Speciation of metals in sediment and water in a river underlain by limestone: role of carbonate species for purification capacity of rivers. $A d v$. Environ. Res. 8, 599-612.

Kumar, A. V., Patil, R. S. and Nambi, K. S. V. (2001) Source apportionment of suspended particulate matter at two traffic junctions in Mumbai, India. Atmos. Environ. 35, 42454251.

Lau, M. M. (1991) Tributyltin antifouling: A threat to Hong Kong marine environment. Archives of Environmental Contamination and Toxicology 20, 299-304.

Liang, G. S., Chou, T. Y. and Han, T. C. (2005) Cluster analysis based on fuzzy equivalence relation. European Journal of Operational Research 166, 160-171.

Lin, Y. P., Teng, T. P. and Chang, T. K. (2002) Multivariate analysis of soil heavy metal pollution and landscape pattern in Changhua county in Taiwan. Landscape and Urban Planning 62, 19-35.

Liu, W. X., Li, X. D., Shen, Z. G., Wang, D. C., Wai, O. W. H. and Li, Y. S. (2003) Multivariate statistical study of heavy metal enrichment in sediments of the Pearl River Estuary. Environ. Pollut. 121, 377-388.

Loska, K., Wiechula, D. and Korus, I. (2004) Metal contamination of farming soils affected by industry. Environ. Int. 30(2), 159-165.

Martin, J. M. and Windom, H. L. (1991) Present and future roles of ocean margins in regulating marine biogeochemical cycles of trace elements. Ocean Marginal Processes in Global Change (Montora, R. F. C., Martin, J. M. and Wollast, R., eds.), 45-68, Wiley, U.K.

Mucha, A. P., Vasconcelos, M. T. S. D. and Bordalo, A. A. (2003) Macro benthic community in the Douro Estuary: relations with trace metals and natural sediment characteristics. Environ. Pollut. 121, 169-180.

Nkono, N. A., Asubiojo, O. L., Ogunsua, O. A. and Oluwole, A. F. (1999) Levels, sources and speciation of trace elements in the surface waters of the Lagos Lagoon. Int. J. Environ. Stud. 56, 215-230.

Pekey, H. (2006) The distribution and sources of heavy metals in Izmit Bay surface sediments affected by a polluted stream. Mar. Pollut. Bull. 52, 1197-1208.

Punj, G. N. and David, W. S. (1983) Cluster analysis in marketing research: Review and suggestion for application. $J$. Mark. Res. 20, 135-148.

Reeder, R. J. (1996) Interaction of divalent cobalt, zinc, cadmium, and barium with the calcite surface during layer growth. Geochim. Cosmochim. Acta 60, 1543-1552.

Rowlatt, S. M. and Lovell, D. R. (1994) Lead, zinc and chromium in sediments around England and Wales. Mar. Pollut. Bull. 28(5), 324-329.

Shin, P. K. S. and Lam, W. K. C. (2001) Development of a marine sediment pollution index. Environ. Pollut. 113, 281291.

Shine, J. P., Ika, R. V. and Ford, T. E. (1995) Multivariate statistical examination of spatial and temporal patterns of heavy metal contamination in New Bedford Harbour marine sediments. Environ. Sci. Technol. 29, 1781-1788.

Stumm, W. and Morgan, J. J. (1996) Aquatic chemistry, chemical equilibria and rates in natural waters. Trace Metals: Cycling, Regulation, and Biological Role, 3rd ed., John Wiley \& Sons, Inc., U.S.A.

Szefer, P. and Kaliszan, R. (1993) Distribution of elements in sediment cores of the Southern Baltic from the point of view of principal component analysis. Studia 1 Materialy Oceanogeczne NR 64. Mar. Pollut. 1, 95-102.

Vogt, N. B. (1990) Multivariate ecotoxicological mapping of the relationships between sediment chemical composition and fauna diversity. The Sci. Total Environ. 90, 149-161.

Wang, H. and McCauley, P. B. (1996) Fuzzy clustering analysis and multi-factorial evaluation for students' imaginative power in physics problem solving. Fuzzy Sets and Systems 78, 95-105.

Zelenka, M. P., Wilson, W. E., Chow, J. C. and Lioy, P. J. (1994) A combined TTFA/CMB receptor modeling approach and its application to air pollution sources in China. Atmos. Environ. 28(8), 1425-1435.

Zwolsman, J. J., van Eck, G. T. M. and Burger, G. (1996) Spatial and temporal distribution of trace metals in sediments from the Scheldt Estuary, South-west Netherlands. Estuar., Coastal Shelf Sci. 43, 55-79. 